\title{
A globalização das produções científicas
}

\author{
Gislene Farias de Oliveiral
}

Resumo: À medida que crescem as exigências para o ingresso em programas de pós-graduações, aumentam também a pressão para que os alunos e professores brasileiros publiquem cada vez mais em periódicos internacionais. Esta situação impulsiona os periódicos nacionais a trabalharem para atender critérios de internacionalização, de forma a se tornarem cada vez mais reconhecidos pela comunidade científica nacional e internacional.

Palavras-Chave: Periódico, Revista científica, Publicações.

\section{The globalization of scientific production}

\begin{abstract}
As they grow the requirements for entry into post-graduate programs also increase pressure for students and Brazilian teachers to publish increasingly in international journals. This boosts national journals to work to serve international criteria in order to become more and more recognized by national and international scientific community.
\end{abstract}

Keywords: Journal, Scientific journal, Publications.

O crescimento nas exigências para o ingresso em programas de pós-graduações, impõem também uma pressão para que os alunos e professores no Brasil, publiquem cada vez mais em periódicos internacionais. Esta situação impõe aos periódicos nacionais, um maior trabalho para atenderem, cada vez mais, os critérios de internacionalização, de forma a tornarem-se cada vez mais reconhecidos pela comunidade científica nacional e internacional.

São muitas as condições que um periódico precisa atender para atrair autores com trabalhos relevantes. Fazer parte de indexadores internacionais de peso, atender critérios de periodicidade e pontualidade, exigência de trabalhos que tenham passado por comitês científicos, dentre outros, não é tarefa simples. Mas para entrar no seleto grupo de periódicos mais atraentes, cientificamente falando, é necessário muito trabalho da equipe editorial.

Torna-se de grande valor as chamadas internacionais e convites aos grupos de pesquisas de universidades de renome. Para isso, há que se pensar em uma série de estratégias de divulgação e acesso dos autores, tais como a facilidade e agilidade nas submissões, publicação e divulgação multilíngue e, ajuste dos custos de revisão e tradução quando necessário, por exemplo.

No caso da Id on Line REVISTA DE PSICOLOGIA, Somente o fato de modernizar a Plataforma, o lay-out, inserir o DOI (Digital object identifier) ,e passar a compor mais e melhores bases de dados, já visualizamos um aumento considerável nas submissões, inclusive de outros países latino-americanos. Porém ainda é grande a procura nacional, em mais de $95 \%$ dos casos. Portanto temos ainda muito trabalho pela frente, junto com os nossos autores e colaboradores.

${ }^{1}$ Doutora em Psicologia Social. Editora-Gerente da Id on Line Revista de Psicologia. E-mail: gislenefarias@ gmail.com. 
Nesta edição, uma série de importantes trabalhos potencializam e evidenciam a qualidade deste periódico científico. Iniciamos com três trabalhos na área da Educação: "Escola e família: aliança na formação do cidadão" de Lopes, REM; "Participar ou não participar, eis a questão, Estudo sobre o engajamento dos estudantes de administração em atividades extracurriculares" de Cassundé, FRSA et al e, "Plano educacional individualizado para alunos com altas habilidades: uma questão de avaliar estratégias na escola regular" de Silva et al. Na sessão Psicologia e Saúde, dois trabalhos merecem destaque: "Saúde e Espiritualidade: as narrativas profissionais na Estratégia Saúde da Família” de Barros Júnior, J. et al e, "Assistência pré-natal: uma avaliação do serviço de saúde no atendimento às gestantes no município de Icó-CE”, de Dantas, VMC et al.

A sessão Administração e Recursos Humanos contou também com dois trabalhos: "Influência da gestão pública na motivação dos professores" de Pereira, DMS e Cassundé, FRSA e, "Planejamento Estratégico situacional em Saúde: um desafio no gerenciamento de uma Unidade Básica de Saúde em Paulo Afonso - BA”, de Silva, DLM e Vieira, SSV., et al.

Outros artigos como "Avaliação de desempenho de servidores públicos efetivos ante as necessidades de excelência em serviço" de Martins, LV e, Cassundé, FRSA e, "A depressão no idoso" de Braga, IB et al. Dois Relatos de Caso: um sobre " Motivação e Satisfação no Trabalho dapolícia Militar: um estudo de caso no sertão pernambucano" de Cassundé, FRSA et al e, "De paciente a terapeuta: a ressignificação do processo saúde-doença e empoderamento na Terapia Comunitária" de Giffoni, FAO.

Ainda fazem parte dessa edição quatro Comments, a saber: "Da melancolia a escrita: um estudo sobre as possibilidades de sublimação", de Silva, DS; "O que vou ser quando crescer? A relação entre atividade profissional e a perspectiva de atuação após o fim do curso de graduação" de Cassundé, FRSA, et al; "Contribuições da antropologia médica à epidemiologia e à pesquisa na área da saúde", de GIFFONI, FA, et al e; "A Percepção do Idoso sobre a saúde e Qualidade de Vida na terceira idade", de Braga, IB, et al.

Portanto, um material muito rico e especial, o qual convido todos a uma agradável leitura.

Gislene Farias de Oliveira

Editora 